\title{
Belajar Baca Al-Quran terhadap Emotional Intelligence (EI) Pada Anak Usia di sekolah Dasar Islam Terpadu
}

\author{
Eka Rokhmiati \\ ${ }^{1,2}$ Program Studi Sarjana Keperawatan \\ Sekolah Tinggi Ilmu Kesehatan Indonesia Maju \\ Jln. Harapan Nomor 50, Lenteng Agung - Jakarta Selatan 12610 \\ Telp: (021) 78894045 Email: eka.rokhmiati@gmail.com
}

\begin{abstract}
Abstrak
Kecerdasan emosional atau sering disebut dengan emotional intelligence terbentuk dari masa kanak-kanak dan stimulasi ketika mereka berinteraksi dalam keluarga, lingkungan dan sekolah. Stimulasi dapat berupa berbagai metode seperti aktivitas fisik atau aktivitas soft skill. Penelitian ini memfokuskan soft skill activity yang belajar membaca Al Quran selama 30 menit. Kegiatan ini dilakukan setiap hari (Senin sampai Jumat), apakah ada hubungan dengan kecerdasan emosi kesejahteraan, pengendalian diri, emosional dan sosial. Sampel yang digunakan terdiri dari 136 siswa yang berusia 9 tahun sampai 10 tahun (rata-rata usia $\mathrm{M}=10,5$, anak laki-laki = 68 anak perempuan $=68$ ). Siswa diperbolehkan mengisi kuesioner yang berisi 36 pertanyaan menggunakan skala Trait emotional intelligence questaniore-Child Form (TEIQue-CF) dengan skala Likert di mana ada kemakmuran, pengendalian diri, emosional dan sosial. Siswa adalah mereka yang masih bersekolah aktif sejak kelas 1 di SDIT tersebut. Ada beberapa arti signifikan dari stimulasi soft skill: pengendalian diri dan sosial. Adapun kesejahteraan dan emosi belum berkembang dengan baik karena usia yang masih relatif muda. Penelitian ini diadopsi dari bentuk kuisioner emosi anak (TEIQue-CF) yang bersifat baku. Emotional intellegence adalah teknik untuk menilai dan melakukan rangsangan ulang, terutama softskill. Kecenderungan seorang anak akan dirangsang jika lingkungan juga melakukan rangsangan seperti itu. Belajar membaca AlQuran adalah salah satu cara untuk menstimulasi softskill untuk meningkatkan emosional intellegence.
\end{abstract}

Kata Kunci

: Kecerdasan Emosional, Sekolah

\begin{abstract}
Emotional intelligence formed from childhood and stimulation while they interact in families, environment and school. The Stimulation can be various methods such as physical activity or soft skill activities. This research focused soft skill activity which learned reading Al Quran for 30 minutes. This activity was do every day (Monday to Friday), whether there were a relationship with the emotional intelligence of welfare, self-control, emotional and social. The sample used consisted of 136 students aged 9 years to 10 years (average age $M=$ 10,5 , boy $=68$ girls $=68$ ). Students were allowed filled questionnaire containing 36 questions using Trait emotional Likert scale in which there is prosperity, self control, emotional and social. Students are who they still that school while he the first elementary islam school. There were several significant meanings of soft skill stimulation: self-control and social. As for the welfare and emotional not yet developed well because of the age that is still relatively young. This research adopted from trait emotional questionnaire child form (TEIQue-CF). Emotional quetion is a technique for assessing and re-doing stimulation, especially soft skills. A child's tendency will be stimulated if the environment also performs such stimulation. Learning to read the Quran is one of way to stimulate Soft skills to improve Emotional Question.
\end{abstract}

Keywords

: Emotional Intellegence, School 


\section{Pendahuluan}

Setiap anak usia sekolah selama tumbuh kembangnya pasti mengalami berbagi aktivitas. Aktivitas yang dimaksud adalah aktivitas fisik dan rohani. Kegiatan yang dilakukan oleh anak usia sekolah di sekolah bervariasi, seperti belajar, bermain, beraktivitas hingga kegiatan sosial. Kegiatan yang dilakukan anak usia sekolah dimulai dari pagi hari sebelum mereka berangkat ke sekolah hingga aktivitas sebelum tidur malam. Situasi tersebut akan mendukung kegiatan aktivitas belajar mengajar pada anak usia sekolah. Perubahan yang terjadi pada anak usia usia 6 sampai 18 tahun sangat luas dan mencakup semua area pertumbuhan dan perkembangan. Anak akan berkembang dan bertumbuh untuk membangun, memperluas, memperhalus, keterampilan fisik, psikososial, kognitif dan moral sehingga ia akan diterima sebagai anggota masyarakat yang produktif. ${ }^{1}$

Aktivitas yang dilakukan anak sedikit banyak mempengaruhi terhadap tumbuh kembang dan bagaimana pribadi terbentuk. Setiap anak yang lahir memiliki naluri dasar yang sama terhadap orang tuanya. Anak yang lahir dan dibesarkan dipengaruhi lingkungan seperti lingkungan sosial, serta kebiasaan aktivitas yang dilakukan disekelilingnya. Orang tuanya serta lingkungan yang menjadikan apakah anak menjadi, yahudi, kristen atau pemuja. Anak menyerap dan belajar dari aktivitas yang diterima seperti kegiatan di sekolah. Sekolah dapat membangun karakter yang ingin dibentuk oleh orangtuanya. Termasuk di antaranya majalah, koran dan internet. ${ }^{2}$

Aktivitas lain yang memberikan manfaat pada anak-anak yaitu aktivitas visual. Salah satu aktivitas visual yaitu aktivitas membaca. Penelitian di Carolina Utara Amerika menggambarkan bahwa anak-anak yang berpartisipasi aktif membaca akan lebih baik memiliki kemampuan akademik. ${ }^{3}$ Aktivitas membaca secara bersama-sama merupakan hal yang mendorong interaksi anak. ${ }^{4}$

Aktivitas yang dilakukan sebelum masuk pada pembelajaran sekolah berhubungan dengan tingkat adaptasi anak di sekolah. Kemampuan beradaptasi terhadap sesuatu merupakan kemampuan atau kecerdasan secara emosional.
Dari penjelasan

kecenderungan arti bahwa kecerdasan emosional adalah kemampuan mengenali perasaan sendiri dan perasaan orang lain, kemampuan memotivasi diri sendiri, kemampuan mengolah emosi dengan baik pada diri sendiri dan orang lain. ${ }^{5}$ Secara optimal, sehingga dia dapat mewujudkan dirinya dan berfungsi sepenuhnya, sesuai dengan kebutuhan pribadinya dan kebutuhan masyarakat.

Perkembangan kepribadian anak merupakan suatu proses multilateral yang kompleks, yang dapat dilihat dari perkembangan motorik, kognitif, dan sosial emosional. Pengalaman yang dialami anak dalam periode ini adalah pengalaman yang signifikan dan memiliki pengaruh yang besar terhadap nilai dan kebiasaan anak dikemudian hari saat dewasa. Saat ini banyak anak-anak gagal dalam membangun hubungan sosial dan tidak dapat mengekspresikan emosi secara verbal. $^{6}$ Keberhasilan dalam hubungan sosial dimasa depan bergantung pada kecerdasan emosional. Kecerdasan emosional lebih penting dibandingkan dengan kecerdasan kognitif. Kecerdasan emosional berkaitan dengan kemampuan individu mengatasi perasaan termasuk kesadaran diri akan perasaan, mengelola perasaan, motivasi diri, identifikasi perasaan, dan mengelola hubungan. ${ }^{7}$

Salovey dan Birnbaum (1989), Forgas dan Moylan (1987), Mayer dan Bremer (1985) mendeskripsikan bahwa teori kecerdasan emosional merupakan proses kognitif adaptif dan individu dapat berpikir rasional tentang emosi. Emosi seperti marah, bahagia, takut, mood, preferensi, dan keadaan tubuh mempengaruhi bagaimana individu berpikir, membuat keputusan, dan melakukan tugas yang berbeda. $^{8}$

Keterampilan emosional mendukung perkembangan sosial dan kognitif pada anakanak. Pengetahuan emosional dapat memprediksi kompetensi akademik dan orientasi tugas bahkan ketika mengendalikan kemampuan verbal. Kemampuan emosional yang buruk dapat mengakibatkan kesulitan sekolah yang berkaitan dengan prestasi akademis dan perilaku antisosial yang terus-menerus. ${ }^{9}$ Kecerdasan emosional dapat diukur secara andal pada masa 
pertengahan dan akhir anak-anak. ${ }^{10,11}$ dan berbeda satu sama lain. ${ }^{12}$

Berdasarkan hasil penelitian studi literature banyak aktivitas fisik yang dilakukan di sebelum aktivitas belajar dilakukan. Dikemukakan juga bahwa adanya aktivitas fisik sebelum aktivitas belajar dapat meningkatkan kecerdasan emosional secara akurat. Peneliti tertarik ingin mengetahui adakah hubungan belajar baca Al Quran sebelum aktivitas pembelajaran terhadap kecerdasan emotional pada anak usia sekolah khusus nya kelas 4 kelas 5 dan kelas 6 di sekolah dasar Islam terpadu (SDIT).

\section{Metode}

Penelitian ini menggunakan tehnik deskriptif korelasi dengan pendekatan cross sectional. Penelitian ini menggunakan kuisioner baku yaitu trait intelegence emotional questionnaire childform (TEIQ-CF). Populasi yang digunakan adalah seluruh siswa Sekolah Dasar Islam Terpadu Al Azhar 46 yang berlokasi di Depok jawa Barat. Responden penelitian ini adalah siswa kelas 4 hingga kelas 6. Sedangkan sampel yang digunakan adalah siswa yang memiliki kriteria inklusi , seperti siswa yang dijadikan responden adalah yang dari awal masuk sekolah tersebut yaitu kelas 1 SD. Kedua responden yang tidak sedang sakit. Data yang digunakan univariat adalah jenis kelamin dan usia dalam bentuk frekwensi dan persentase. Analisis bivariat penelitian ini melihat hubungan belajar baca Al Quran dengan emotional intellenge adalah yang di analisis dengan chi square.

\section{Hasil}

Penelitian ini dilakukan bulan Mei 2018, dengan analisis data univariat . Univariat emotional intellegence di lakukan dengan menggunakan TEIQ-CF tersebut dibawah ini;

Tabel 1. Distribusi Frekwensi Jenis Kelamin Responden belajar baca Al Quran Terhadap emotional intelligence (EI)

\begin{tabular}{lll}
\hline Jenis Kelamin & Frekuensi & $\%$ \\
\hline Laki Laki & 68 & 50 \\
\hline
\end{tabular}

\begin{tabular}{lll}
\hline Perempuan & 68 & 50 \\
\hline Total & $\mathbf{1 3 6}$ & $\mathbf{1 0 0}$ \\
\hline
\end{tabular}

Hasil univariat jenis kelamin seimbang antara jenis kelamin laki-laki dan jenis kelamin perempuan.

Tabel 2. Distribusi Frekwensi usia Responden belajar baca Al Quran Terhadap emotional intelligence (EI)

\begin{tabular}{lll}
\hline Usia & Frekuensi & \% \\
\hline 9 tahun & 46 & 33.82 \\
\hline 10 tahun & 40 & 29.41 \\
\hline 11 tahun & 30 & 22.06 \\
\hline 12 tahun & 20 & 14.71 \\
\hline Total & $\mathbf{1 3 6}$ & $\mathbf{1 0 0}$ \\
\hline
\end{tabular}

Hasil penelitian menujukan bahwa dari 136 siswa terbanyak usia 9 tahun sebesar $33,82 \%$.

Tabel 3. Frekuensi Belajar baca Al Quran (BBQ)

\begin{tabular}{lll}
\hline $\begin{array}{l}\text { Belajar } \\
\text { baca } \mathbf{A l} \\
\text { Quran }\end{array}$ & Frekuensi & $\mathbf{\%}$ \\
\hline Rutin & 124 & $91,17 \%$ \\
\hline Kurang rutin & 12 & $8,82 \%$ \\
\hline Total & $\mathbf{1 3 6}$ & $\mathbf{1 0 0}$ \\
\hline
\end{tabular}

Hasil penelitian menunjukan bahwa anak rutin belajar baca Al Quran (Senin hingga Jumat) selama 30 menit sedangkan yang kurang rutin dikarenakan karena ada halangan seperti sakit atau ijin karena ada keperluan. Hal ini terlihat dari daftar absensi BBQ.

Tabel 4. Hubungan belajar baca Al Quran terhadap perkembangan emotional intelligence (EI)

\begin{tabular}{|c|c|c|c|}
\hline $\begin{array}{l}\text { Hubungan Belajar } \\
\text { baca Al Quran } \\
\text { dengan } \\
\text { Perkembangan } \\
\text { emotional quetion }\end{array}$ & $\begin{array}{l}\text { CI } \\
\text { Upper }\end{array}$ & $\begin{array}{l}\text { CI } \\
\text { Lower }\end{array}$ & $P$ value \\
\hline Rutin & \multirow{2}{*}{6,625} & \multirow{2}{*}{0,02} & \multirow{2}{*}{0.000} \\
\hline Kurang rutin & & & \\
\hline
\end{tabular}

Hasil analisis bivariat menggunakan $\mathrm{Chi}$ Squere. Menunjukan pada convidence interval 
(CI) bahwa terdapat pengaruh 6 kali anak mengalami perkembangan emosional dibanding yang kurang rutin belajar baca Al Quran intelligence. Ditunjukan dengan kebermaknaan ada hubungan rutinitas BBQ dengan $\mathrm{P}$ Value < 0,05 .

Tabel 5. Distribusi pertanyaan menggunakan TEIQue-CF

\begin{tabular}{lc}
\hline Belajar baca Al Quran & P Value \\
\hline $\begin{array}{l}\text { Saya selalu berusaha berada dalam } \\
\text { suasana hati yang baik. }\end{array}$ & 0,000 \\
\hline $\begin{array}{l}\text { Saya senang bertemu orang baru. } \\
\text { Saya merasa sulit memulai tahun }\end{array}$ & 0,000 \\
ajaran baru. & 0,000 \\
\hline $\begin{array}{l}\text { Saya bangga dengan diri saya. } \\
\text { Ketika saya merasa sedih, saya } \\
\text { mencoba mengerjakan hal lain. }\end{array}$ & 0,001 \\
\hline $\begin{array}{l}\text { Saya sering merasa sedih. } \\
\text { mengungkapkan perasaan. }\end{array}$ & 0,000 \\
\hline $\begin{array}{l}\text { Jika saya senang ke orang, saya } \\
\text { akan memberitahu mereka. }\end{array}$ & 0,013 \\
\hline $\begin{array}{l}\text { Saya berteman dengan semua } \\
\text { orang. }\end{array}$ & 0,000 \\
\hline $\begin{array}{l}\text { Sang lain. } \\
\text { bayana sering marah. }\end{array}$ & 0,000 \\
\hline $\begin{array}{l}\text { Teman-teman di sekolah senang } \\
\text { bermain dengan saya. }\end{array}$ & 0,000 \\
\hline $\begin{array}{l}\text { Saya sering merasa tidak bahagia. } \\
\text { Saya sering tidak berfikir sebelum }\end{array}$ & 0,0000 \\
\hline
\end{tabular}

Jika saya harus melakukan sesuatu, 0,000 saya tahu saya dapat melakukannya dengan sangat baik.

Saya mudah marah. 0,000

Saya mencoba mengerjakan tugas 0,001 sekolah sebaik saya bisa.

Sangat mudah bagi saya $\quad 0,000$

mengutarakan perasaaan.

Saya tidak suka menunggu sesuatu $\quad 0,003$ yang saya inginkan.

\begin{tabular}{lc}
\hline Saya adalah anak yang ceria. & 0,003 \\
\hline Saya tidak suka rajin belajar. & 0,000 \\
\hline $\begin{array}{l}\text { Saya sedih jika tumbuh jadi } \\
\text { dewasa. }\end{array}$ & 0,000 \\
\hline $\begin{array}{l}\text { Kebanyakan orang menyukai saya. } \\
\text { Saya tidak suka melakukan hal }\end{array}$ & 0,000 \\
yang sulit. & 0,001 \\
\hline $\begin{array}{l}\text { Saya tidak bisa mengontrol } \\
\text { perasaan. }\end{array}$ & 0,000 \\
\hline $\begin{array}{l}\text { Saya terbiasa dengan orang baru. } \\
\text { Saya tidak menemukan kata-kata } \\
\text { yang tepat untuk mengutarakan } \\
\text { perasaan. }\end{array}$ & 0,003 \\
\hline $\begin{array}{l}\text { Saya tidak suka mencoba hal baru. } \\
\text { orang lain. }\end{array}$ & 0,003 \\
$\begin{array}{l}\text { Saya suka bersama dengan orang } \\
\text { lain. }\end{array}$ & 0,000 \\
\hline $\begin{array}{l}\text { Saya tahu bagaimana } \\
\text { menukkan rasa peduli saya ke }\end{array}$ & 0,000 \\
\hline
\end{tabular}

Saya sering bingung terhadap $\quad 0,000$
perasaan yang saya alami.

Saya merasa sulit untuk $\quad 0,000$
memahami apa yang orang lain rasakan.

Jika saya tidak melakukan sesuatu $\quad 0,000$ dengan baik, saya tidak suka mencoba melakukannya kembali.

Biasanya, saya berfikir sebelum berbicara. 
Analisa hasil TEIQ-CF non parametrik menunjukan $\mathrm{p}$ value $<0,05$, manandakan adanya proses perkembangan emotional intelligence (EI)

\section{Pembahasan}

\section{Frekwensi jenis kelamin dan usia}

Frekwensi jenis kelamin pada penelitian ini masing masing dominan baik anak laki-laki maupun perempuan. Begitu juga dengan usia anak dipenelitian ini dominan berada di usia 9 tahun. Sejalan dengan penelitian yang dilakukan oleh $^{13}$ mengemukan bahwa perkembangan EQ dan IQ berbeda. IQ berkembang dan ada sejak lahir dan merupakan kasus genetik. ${ }^{14}$ Sedangkan EQ berkembang melalui proses dan stimulasi yang ditemui di lingkungan pada 10 tahun pertama. Jenis kelamin dan usia anak kadang kala mempengaruhi

\section{Belajar baca Al Quran dengan perkembangan Emotional intelligence}

Kegiatan yang dilakukan anak untuk berkembang secara fisik dan kuat secara jasmani dengan melakukan aktivitas fisik sebelum pembelajaran sekolah dimulai. Kegiatan aktivitas fisk dapat berupa olah raga atau berjalan 30- 60 menit sebelum pembelajaran. Aktivitas ini terbukti mengurangi keterlambatan dan meningkatkan kerja jantung. ${ }^{15}$ Selain kegiatan fisik, aktivitas yang dapat dilakukan anak adalah dengan menari. Kegiatan menari merupakan kegiatan sosial karena bisa dilakukan secara sendiri atau bersama. Fokus yang ingin dicapai dari kegiatan menari adalah keterampilan motorik dan emosi. Hasil dari penelitian ini membuktikan bahwa dengan menari akan meningkatkan keseimbangan antara kontrol diri dan kepercayaan anak. ${ }^{7}$

Aktivitas BBQ dapat menimbulkan minat gemar membaca Al Quran, sehingga dapat membina dan membimbing akhlak (16). Hal ini sejalan dengan Peraturan Menteri Pendidikan dan Kebudayaan Nomor 23 Tahun 2015. Salah satu program di dalam gerakan tersebut adalah "kegiatan 15 menit membaca buku non pelajaran sebelum waktu belajar dimulai". Program ini dilaksanakan untuk menumbuhkan minat baca peserta didik dapat meningkatkan keterampilan membaca agar pengetahuan dapat dikuasai secara lebih baik. Materi baca berisi tentang nilai-nilai budi pekerti, berupa kearifan lokal, nasional, dan global yang akan disampaikan sesuai dengan jenjang pendidikan peserta didik. ${ }^{17}$

Emotional intelligence merupakan kapasitas dari emosi dan merupakan hasil pemikiran. Seorang individu yang memiliki emotional intellenge yang tinggi akan memiliki hubungan sosial yang baik sehingga dapat memecahkan masalah dengan cepat, mudah bergaul dengan orang lain, pandai berkomunikasi dan pandai bersosialisasi. Hal ini sesuai dengan penelitian yang diutarakan oleh ${ }^{18}$ bahwa EI dipengaruhi oleh kegiatan adan aktivitas sehari hari serta tingkah laku non verbal dari sekitarnya. Belajar baca Al Quran yang rutin dapat meningkatkan kemampuan personal yang baik hal ini juga dikemukakan ${ }^{19}$ bahwa kegiatan yang rutin $\mathrm{BBQ}$ dapat menghasilkan fisik yang kuat karena mental yang sehat, hubungan sosial yang baik serta personal leadership yang sempurna.

\section{Trait Emotional Intelligence Child Form (TEIQue-CF)}

Seiring sejalan dengan hasil dari kusioner yang dibagikan, menunjukan bahwa persepsi anak terhadap sesuatu dapat diatur dengan baik. Dengan $\mathrm{p}$ value $<0,05$, menandakan bahwa dari TEIQue bermakna terhadap setiap jawabanya yang diberikan. Hal ini erat hubungannya proses bertambahnya usia mereka, maka akan berkembang juga emotional intelligence (EI). Terbentukanya konsep diri matur, kognitif yang berkembang. Mereka akan tumbuh menjadi anak yang tinggi secara self confidence. ${ }^{20}$ Pembentukan self confidence yang baik diawal kanak kanak akan membentuk pribadi remaja yang matur. Karena awal remaja merupakan merupakan sesuatu yang akan menunjang kelak jika dewasa seperti penyelesaian konflik, membina hubungan yang harmonis dan mempertahankan konsep diri yang baik. ${ }^{21}$

\section{Kesimpulan}

Dari hasil pembahasan diatas menunjukan bahwa aktivitas belajar baca Al Quran adalah suatu aspek yan tepat untuk memberikan stimulasi perkembangan emotional intelligence bagi anak usia sekolah. Perkembangan BBQ 
merupakan aspek soft skill sebagai pondasi pembentukan self confidence anak dikemudian hari.

Stimulasi yang dilakukan secara rutin di BBQ terbukti secara uji bivariat bermakna terhadap hasil emotional intelligence.

Trait emotional intelligence questanioreChild Form yang sudah baku dan peneliti sudah mendapat ijin dari Mavroveli \& Petrides (Institute of Education, University of London) untuk dapat digunakan dan hasilnya menujukan bahwa secara terus menerus emotional intelligence pada tahap anak akan berkembang seuai dengan tahapan tumbuh kembangnya.

\section{Saran}

Anak usia sekolah merupakan tahapan keberlanjutan tumbuh kembang setelah anak usia prasekolah. Pada Usia sekolah anak mendapat tugas dan tanggung jawab sedikit lebih banyak dibanding usia prasekolah. Anak usia sekolah mendapat tanggung jawab terhadap pendidikan dan dan kemampuan berinteraksi dengan lingkungan di sekolahnya.

Hasil yang diinginkan oleh setiap anak, orangtua maupun guru adalah anak dapat beradaptasi dan secara bijak dapat mengatasi situasi saat beradaptasi.

Karena nya penting halnya jika sebelum aktivitas belajar mengajar di sekolah diterapkan hal menyenangkan anak dan merefresh anak sejenak sebelum aktivitas belajar. Aktivitas softskill paling tepat karena membuka pemikiran dan perasaan anak.

\section{Daftar Pustaka}

1. Li Y, Yu D. Development of Emotion Word Comprehension in Chinese Children from 2 to 13 Years Old: Relationships with Valence and Empathy. PLoS One. 2015;10(12):1-19.

2. Ul Z, Sodhar A, Shaikh AG, Sodhar K. An Analysis of the Trend of Muslims to Communicate their Faith Tradition to their Children in Pakistan. 2017;42:99-110.

3. Fleury VP, Miramontez SH, Hudson RF, Schwartz IS. Promoting active participation in book reading for preschoolers with Autism Spectrum Disorder: A preliminary study. Child Lang Teach Ther. 2014;30(3):273-88.
4. Hudson ME, Test DW. Evaluating the Evidence Base of Shared Story Reading to Promote Literacy for Students With Extensive Support Needs. Res Pract Pers with Sev Disabil. 2011;36(1):34-45.

5. Ontario Physical and Health Education Association. Daily Physical Activity in Schools. 2005;1-70. Available from: https://www.edu.gov.on.ca/eng/teachers/dpa1 $-3 . p d f$

6. Utara P. Hubungan tipe pola asuh orang tua dengan. J Keperawatan Anak [Internet]. 2017;1(1):188-99. Available from: http://journal2.um.ac.id/index.php/icsar/articl e/view/381\%0Ahttp://journal.lib.unair.ac.id/i ndex.php/JN/article/view/584

7. Walter O, Sat E. Dance and its influence on emotional self-control and regulation and emotional intelligence abilities among early childhood-aged children. Int $\mathrm{J}$ Arts Sci. 2013;6(4):77-97.

8. Brackett MA, Rivers SE, Salovey P. Emotional Intelligence: Impications for Personal, Social, Academic, and Workplace Success. Sos Pers Psychol Compass. 2011;5(1):88-103.

9. Qualter P, Gardner KJ, Pope DJ, Hutchinson JM, Whiteley HE. Ability emotional intelligence, trait emotional intelligence, and academic success in British secondary schools: A 5year longitudinal study. Learn Individ Differ. 2012;22(1):83-91.

10. Barlow A, Qualter P, Stylianou M. Relationships between Machiavellianism, emotional intelligence and theory of mind in children. Pers Individ Dif. 2010;48(1):78-82.

11. Mavroveli S, Petrides K V., Sangareau Y, Furnham A. Exploring the relationships between trait emotional intelligence and objective socio-emotional outcomes in childhood. $\mathrm{Br} \quad \mathrm{J}$ Educ Psychol. 2009;79(2):259-72.

12. Qualter P, Barlow A, Stylianou MS. Investigating the relationship between trait and ability emotional intelligence and theory of mind. Br J Dev Psychol. 2011;29(3):43754.

13. Shipley N, Jackson M, Segrest S. The effects of emotional intelligence, age, work experience, and academic performance. Res High Educ J [Internet]. 2010;1-18. Available from:

http://www.jid.aabri.com/manuscripts/10535. pdf

14. Albanese O, De Stasio S, Di Chiacchio C, Fiorilli C, Pons F. Emotion comprehension: The impact of nonverbal intelligence. J Genet Psychol. 2010;171(2):101-15. 
15. Stylianou M, van der Mars H, Kulinna PH, Adams MA, Mahar M, Amazeen E. BeforeSchool Running/Walking Club and Student Physical Activity Levels: An Efficacy Study. Res Q Exerc Sport. 2016;87(4):342-53.

16. Faradina N. Pengaruh Program Gerakan Literasi Sekolah Terhadap Minat Baca Siswa Di Sd Islam Terpadu Muhammadiyah anNajah Jatinom Klaten. J Hanata Widya. 2017;6:60-9.

17. Artha NMWI, Supriyadi. Hubungan Antara Kecerdasan Emosi dan Self Efficacy dalam Pemecahan Masalah Penyesuaian Diri Remaja Awal. J Psikol Udaya. 2013;1(1):190-202.

18. Ensari P. How to Improve Emotional Intelligence and Social Skills among Adolescents : The Development and Test of a New Microexpressions Training. 2017;21125.

19. Dalam AAN, Pemahaman M, Anak AANP. PENERAPAN METODE PEMBELAJARAN BACA-TULIS Oleh : Ety Kustiwi JURUSAN PENDIDIKAN AGAMA ISLAM FAKULTAS TARBIYAH UNIVERSITAS ISLAM NEGERI ( UIN ) MALANG LEMBAR PERSETUJUAN PENERAPAN METODE PEMBELAJARAN BACA-TULIS AL- QUR , AN DALAM MENINGKATKAN PEMAHAMAN BACA. 2008 ;

20. Banjac S, Hull L, Petrides K V, Mavroveli S. Validation of the Serbian adaptation of the Trait Emotional Intelligence QuestionnaireChild Form ( TEIQue - CF ). 2016;49(179018):375-92.

21. Hockenberry MJ, Wilson D. Wong's essentials of pediatric nursing. 9th editio. St. Louis, Missouri: Mosby Elsevier; 2013. 